\title{
Artigos
}

\section{Sumak Kawsay ou Buen Vivir? Os novos fundamentos constitucionais nativos e a reforma das políticas sociais no Equador da "Revolução Cidadã"1}

Carlos Aurélio Pimenta de Faria*

\section{Resumo}

O artigo tem o objetivo de avaliar se e como, ao longo do governo de Rafael Correa, o sistema de proteção social equatoriano tem sido reconfigurado e expandido em atenção à plataforma ou ideal do Sumak Kawsay (SK) ou Buen Vivir (BV), como prescrito pela nova Constituição do país e como explicitado em todos os Planos Nacionais de Desenvolvimento. O foco do trabalho recairá sobre as políticas de assistência social e de educação. Para tanto, o artigo está organizado da seguinte maneira: na primeira seção, buscamos definir SK ou BV, discutindo a genealogia do termo, suas variantes e controvérsias. Na segunda seção, trataremos da institucionalização do conceito de SK/BV e da maneira como ele foi transformado em diretriz fundamental da ação estatal no Equador, desde os planos de governo da Aliança PAIS até sua incorporação na Constituição de 2008 e nos Planos Nacionais de Desenvolvimento. Na terceira seção, por fim, questionamos, com base em uma apreciação das rupturas e continuidades na provisão de assistência social e de educação, em que medida o novo e amplamente propalado conceito de SK/BV tem balizado a atuação do governo da Revolução Cidadã no campo da política.

\footnotetext{
${ }^{1} \mathrm{O}$ autor agradece ao CNPq e à Fapemig pelos recursos para o desenvolvimento da pesquisa da qual o presente trabalho é um subproduto. $\mathrm{O}$ autor agradece também a Pedro Zucheratto Castro pela assistência na coleta dos dados. Uma versão anterior deste artigo foi apresentada no GT Políticas Públicas do 39º Encontro Anual da Anpocs, Caxambu, MG, 26 a 30 de outubro de 2015. Agradecimentos são também devidos, pelos comentários e críticas, aos participantes do GT, muito especialmente a Marta Arretche e Renata Bichir. A redação do artigo foi finalizada em outubro de 2015 .

* Carlos Aurélio Pimenta de Faria é Doutor em Ciência Política pelo Instituto Universitário de Pesquisas do Rio de Janeiro (IUPERJ), desde 1997; e professor e pesquisador do Programa de Pósgraduação em Ciências Sociais da Pontifícia Universidade Católica (PUC) - Minas Gerais. E.mail: carlosf@pucminas.br.
} 
social.

\section{Palavras-Chave}

Buen vivir. Equador. Políticas Sociais.

\section{Abstract}

The article aims to assess if and how, during Rafael Correa's mandate, the equatorial social protection system has been reconfigured and expanded regarding the Sumak Kawsay (SK) or Buen Vivir (BV) platform or ideal, as assigned by the county's new Constitution and exposed in all of the National Development Plans. The work's focus will reflect the social assistance and education policies. To do so, the article is organized as follows: In the first section, we try to define SK/BV, discussing the term's genealogy, its variants and controversies. In the second section, we approach the institutionalization of the SK/BV concept and the way it has been transformed into the fundamental guideline of state action in Ecuador, since PAIS Alliance's government plans into its incorporation in the 2008 Constitution and the National Development Plans. Lastly, in the third section, we question, based on an appraisal of ruptures and continuities in the social assistance and education provision, which way the new and widely propagated SK/BV concept has indicated the government's action of Citizen Revolution in the social politics field.

\section{Keywords}

Buen Vivir. Ecuador. Social Politics.

\section{Introdução}

O Equador é um pequeno país andino com uma população predominantemente mestiça de quase 16 milhões de habitantes, pouco mais da metade da população peruana. Até um passado relativamente recente, o país havia se notabilizado no plano internacional principalmente por sua acentuada instabilidade política. Afinal, entre 1996 e 2006, quando Rafael Correa foi eleito pela primeira vez, o país foi governado por não menos 
que oito presidentes diferentes e por duas juntas de salvação nacional ${ }^{2}$. A ascensão de Correa e de seu partido/movimento Aliança País (Pátria Altiva y Soberana) à presidência trouxe ao Equador não apenas estabilidade política, mas também uma inesperada visibilidade internacional. Para muitos de seus críticos atuais, porém, essa estabilidade teria sido conseguida à custa de crescente autoritarismo, concentração de poderes e populismo.

Atualmente em seu terceiro mandato consecutivo, o líder da autoproclamada "Revolução Cidadã" (e do governo mais longevo da história republicana do país) tem ocupado analistas, observadores e militantes internacionais tanto por seus supostos defeitos quanto pelo caráter não raro inovador de algumas das novas instituições e políticas públicas por ele patrocinadas no Equador. Para os seus críticos, hoje em número crescente tanto no plano doméstico como no internacional, destaca-se o seu papel como expoente da nova esquerda "bolivariana" da América Latina ${ }^{3}$, como liderança "tecnopopulista" (TORRE, 2013a e 2013b) ou, morto Hugo Chávez, como el secreto cabeza de la familia del Socialismo del Siglo XXI (MENDONZA; MONTANER; LLOSA, 2014; p.117). Por outro lado, tornaram-se objeto de grande curiosidade internacional (e também de muita admiração): as profundas inovações trazidas pela Constituição de 2008, nos planos jurídico, institucional e conceitual, como veremos adiante; a política ambiental e de direitos humanos; o ativismo, desenvoltura e caráter revisionista de sua política externa (ZEPEDA; EGAS, 2011; AYLLÓN; DOLCETTI, 2014); e a revalorização das culturas ancestrais, cristalizada na transformação do Sumak Kawsay (SK) ou Buen Vivir (BV) em princípio orientador da ação estatal. Talvez se possa dizer que foi precisamente a centralidade dada pelo governo

\footnotetext{
${ }^{2}$ No contexto internacional, destacou-se também a dolarização oficial da economia equatoriana, ocorrida em 2000, após uma aguda crise econômica, que levou a uma emigração maciça. Talvez paradoxalmente, a dolarização ainda está vigente, hoje, no governo da autoproclamada Revolução Cidadã, que assume, em sua política externa, um posicionamento claramente anti-hegemonista e anti-norte-americano.

${ }^{3}$ A tese das duas esquerdas latino-americanas do século XXI, que teve como precursores Petkoff (2005) e Castañeda (2006), propôs a distinção entre um grupo de lideranças e partidos mais pragmático, a "esquerda certa" (the right left) de Castañeda, que chegou ao poder no Chile e no Brasil, e um grupo bolivariano, ideológico ou populista, a "esquerda errada" (the wrong left), que governa a Venezuela, a Argentina, a Bolívia e, a partir de 2007, também o Equador. Para análises menos maniqueístas e mais matizadas da "virada à esquerda" ou da "onda rosa" latino-americana, ver, entre outros: Cameron (2009), Silva (2010) e Cameron e Hershberg (2010).
} 
da Revolução Cidadã ao princípio, ideal ou plataforma do Sumak Kawsay/ Buen Vivir (SK/BV) o fenômeno catalisador dessas inovações políticas e institucionais ${ }^{4}$.

O presente trabalho tem o objetivo de discutir se e como, ao longo do governo de Rafael Correa, o sistema de proteção social equatoriano tem sido reconfigurado e expandido em atenção à plataforma ou ideal do Sumak Kawsay (SK) ou Buen Vivir (BV), como prescrito pela nova Constituição do país e como explicitado em todos os Planos Nacionais de Desenvolvimento. O foco do trabalho recairá sobre as políticas de assistência social e de educação. Para tanto, o artigo está organizado da seguinte maneira: na primeira seção, buscamos definir SK ou BV, discutindo a genealogia do termo, suas variantes e controvérsias. Na segunda seção, trataremos da institucionalização do conceito de SK/BV e da maneira como ele foi transformado em diretriz fundamental da ação estatal no Equador, desde os planos de governo da Aliança PAIS até sua incorporação na Constituição de 2008 e nos Planos Nacionais de Desenvolvimento. Na terceira seção, por fim, questionamos, com base em uma apreciação das rupturas e continuidades na provisão de assistência social e de educação, em que medida o novo e amplamente propalado conceito de $\mathrm{SK} / \mathrm{BV}$ tem balizado a atuação do governo da Revolução Cidadã no campo da política social.

\section{Sumak Kawsay / Buen Vivir: Definições, Genealogia e Controvérsias de uma "Tradição Inventada"}

Ainda que o termo kichwa Sumak Kawsay (SK) seja usualmente traduzido para o castelhano como "Buen Vivir" (BV) (ou Bom Viver, em português), é grande a polêmica que essa tradução suscita ${ }^{5}$. Adiante, trataremos das

\footnotetext{
${ }^{4} \mathrm{Na}$ Bolívia de Evo Morales, o reconhecimento, valorização e institucionalização de um conceito (ou plataforma de ação política) similar ao Sumak Kawsay (Buen Vivir), o suma qamaña (ou Vivir Bien, como traduzido pela nova Constituição boliviana de 2009), de origem aymara, é um processo que guarda fortes paralelismos com a experiência equatoriana discutida neste artigo (ver, entre outros, Artaraz e Calestani, 2015). Vale destacar, de passagem, que para esses autores "intellectuals of Aymara origin (...) have written extensively on suma qamaña, whereas not much has been produced, for example, on the Quechua equivalent, sumak kawsay" (p.220-221).

${ }^{5} \mathrm{O}$ kichwa é uma das variedades da língua quéchua, variedade essa falada, principalmente, no Equador e na Colômbia.
} 
controvérsias relativas ao uso do termo e à sua genealogia e discutiremos a possibilidade de compreendermos o SK como uma "tradição inventada". $\mathrm{Na}$ próxima seção, analisaremos a sua aplicabilidade como diretriz governamental e como princípio orientador da ação estatal no Equador da Revolução Cidadã. Antes, porém, devemos apresentar um balanço rápido da problemática definicional, recordando, não obstante, que esse continua sendo um debate em aberto.

De maneira preliminar, talvez se possa sugerir que o conceito Sumak Kawsay (SK) (e suas variações, apresentadas a seguir) representa e sintetiza hoje as aspirações de muitos povos latino-americanos, podendo ser definido, de modo minimalista e por certo menos controvertido, como uma "forma de vida em harmonia com a natureza e com os outros seres humanos" (HIDALGO-CAPITÁN; CUBILLO-GUEVARA, 2014; p.26, tradução nossa). É uma definição similar a essa que aparece no Preâmbulo da Constituição Equatoriana de 2008, quando se afirma que "nosotras e nosotros, el pueblo soberano del Ecuador", "decidimos construir una nueva forma de convivencia ciudadana, en diversidad y armonia con la naturaleza, para alcanzar el buen vivir, el sumak kawsay" (ASAMBLEA CONSTITUYENTE, 2008; p.15).

Para vários autores, como Macas (2010) e Monosalvas (2014), entre outros, contudo, não seria precisa a tradução do termo kichwa SK como Buen Vivir, uma vez que sumak é um adjetivo superlativo que se refere a um sentido de plenitude, completude e excelência. Assim, a tradução mais adequada de SK seria "estado de plenitud de toda la comunidad vital", "plenitud de la vida" ou "vida plena”. Segundo essa crítica, Buen Vivir seria traduzido mais adequadamente em kichwa como "alli kausay" (nesse caso, como em outros, diferenças nas grafias são recorrentes) (MONOSALVAS, 2014).

O conceito de sumak kawsay tem sido amplamente divulgado, quase como um mantra, e não apenas nos países andinos, como guia programático para a construção de um modo de vida alternativo ao onipresente american way of life, que seria insustentável, predador e "etnocida" (BRETÓN; CORTEZ; GARCIA, 2014). O SK seria derivado das ontologias relacionais andinas, andino-amazônicas e afrodescendentes, as fontes divergem, "invisibilizadas durante siglos" (idem, p.9). Também é recorrente a afirmação do SK como uma ruptura conceitual e programática com a concepção (ou fixação) euroamericana de progresso e de crescimento. O SK seria uma "oportunidade para se construir coletivamente um novo regime de desenvolvimento" (ACOSTA, 2009), um regime alternativo àquele que impregna a modernidade ocidental, tida como "caduca, monolítica, excludente e 
unilinear" (BRETÓN; CORTEZ; GARCIA, 2014). O empreendimento, que chega a ser visto como uma "insurgência político-epistêmica" (WALSH, 2010), é pensado, de forma reiterada, não apenas como pós-neoliberal, mas também como pós-desenvolvimentista e decolonial. Se o SK busca valorizar a pluralidade dos modos de vida, que redundou, inclusive, no reconhecimento constitucional do Equador (e também da Bolívia) como um Estado Plurinacional e intercultural, o conceito ou plataforma pretende promover também a "desmaterialização da vida".

O termo kichwa Sumak Kawsay (SK), convém recordarmos, tem sinônimos ou equivalentes em diversas outras línguas nativas, como, por exemplo: allin kawsay (em quéchua), suma qamaña (em aymara; esse é o termo prevalecente na Bolívia); teko kavi (em guarani) e kume mogen (na língua mapuche) (ESTERMANN, 2013). Segundo Recasens (2014), essas expressões significariam "uma vida digna, ainda que austera, que concebe o bem-estar de forma holística, identificando-o com a harmonia com o entorno social (a comunidade), com o entorno ecológico (a natureza) e com o entorno sobrenatural (os Apus ou Achachilas e demais espíritos de um mundo encantado)" (p.58, tradução nossa). No que concerne ao comunitarismo dos povos autóctones, suas bases históricas, ainda que também elas eventualmente idealizadas, remontam à tradição de gestão compartida dos recursos, às formas de trabalho coletivo, como a minka, e a alguns sistemas de cargos (RECASENS, 2014; p.68, rodapé 12).

Em uma ampla e recente revisão bibliográfica, que procura sistematizar os "seis debates abertos sobre o sumak kawsay", Hidalgo-Capitán e CubilloGuevara (2014) afirmam ser possível sintetizar da seguinte maneira as disputas acerca de seu significado. Haveria "pelo menos" três grandes correntes de pensamento dedicadas à elaboração do conceito de SK/BV e à discussão acerca de sua aplicabilidade atual, quais sejam: (a) a socialista e estatista, (b) a ecologista e pós-desenvolvimentista e (c) a indigenista e

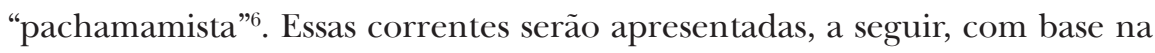
revisão mencionada, mas incorporando outros exemplos e questões. Note-se

\footnotetext{
${ }^{6}$ Pacha Mama ou Mãe Terra é a deidade principal de vários povos andinos, frequentemente associada à fertilidade e ao feminino. Ela é o símbolo da unidade indissolúvel entre todos os seres vivos. No Preâmbulo da Constituição Equatoriana de 2008, afirma-se: "Celebrando a la naturaleza, la Pacha Mama, de la que somos parte y que es vital para nuestra existencia (...) decidimos construir (...)" (ASAMBLEA CONSTITUYENTE, 2008; p.15).
} 
que representantes dessas três correntes também divergem quanto à melhor tradução para os termos originais kichwa e aymara, bem como acerca do paradigma cultural ao qual pertence o SK.

Os representantes da vertente "socialista e estatista" destacam a gestão política do SK e sua instrumentalização pelo Estado no sentido da busca de superação do capitalismo. Valorizando a ênfase comunitária do SK e das tradições andinas ancestrais, essa corrente relega a um plano secundário as igualmente importantes questões ambiental, cultural e identitária. O novo sistema socioeconômico pós-capitalista a ser erigido a partir das diretrizes e ideais do SK tem recebido uma diversidade de denominações, tais como: socialismo do sumak kawsay ou do Buen Vivir ; biossocialismo republicano $e$ bioigualitarismo ciudadano. Essa variante andina do socialismo, mais do que apregoar um retorno ou revalorização das concepções, cosmogonia e modos de vida indígenas, afirma que o conceito de SK deveria ser complementado por aportes do variado pensamento neomarxista contemporâneo. Os representantes dessa vertente, que inspira tanto o governo de Rafael Correa quanto o de Evo Morales, são, principalmente, intelectuais neomarxistas latino-americanos e europeus e políticos socialistas vinculados aos governos do Equador e da Bolívia. São exemplos de destaque: José Luis Corragio, o vice-presidente boliviano Álvaro Garcia-Linera, Pedro Páez, Ricardo Patiño, Marta Harnecker, Atilio Borón, Boaventura de Souza Santos, François Houtart e Valter Pomar. Ainda segundo Hidalgo-Capitán e Cubillo-Guevara (2014), as principais críticas endereçadas à vertente socialista e estatista dizem respeito a sua baixa sensibilidade para as questões ambientais e para as reivindicações e demandas dos povos indígenas, bem como à sua defesa do recurso ao extrativismo como elemento da transição para a sociedade do Buen Vivir.

A segunda corrente foi denominada "ecologista e pós-desenvolvimentista". Cabe, contudo, fazer a ressalva de que nem todos os pós-desenvolvimentistas associados a essa vertente são ecologistas e que nem todos os ecologistas são pós-desenvolvimentistas. Central a essa corrente é não apenas a questão da

\footnotetext{
${ }^{7}$ O termo "socialismo do Buen Vivir" é amplamente utilizado em publicações oficiais equatorianas, principalmente da estratégica Secretaria Nacional de Planificación y Desarrollo (SENPLADES). O Programa de Governo da Aliança PAIS 2013-2017 é intitulado Gobernar para profundizar el cambio: 35 propuestas para el Socialismo del Buen Vivir.
} 
preservação da natureza, mas também a construção participativa do SK/ $\mathrm{BV}$, que incluiria aportes indigenistas, socialistas, feministas, teológicos e, principalmente, ecologistas. Seus representantes falam de uma "utopia por (re)construir" de maneira participativa e respeitando as especificidades locais (ACOSTA, 2010) e de "alternativas ao desenvolvimento", em vez de "alternativas de desenvolvimento" (GUDYNAS, 2011 e 2013). O conceito de SK/BV se constituiria, assim, como uma "colagem pós-moderna" de concepções e aspirações indígenas, camponesas, sindicalistas, cooperativistas, solidárias, feministas, pacifistas, ecologistas, teológico-liberacionistas, decolonialistas, entre outros, que se materializaria de maneira distinta em cada coletividade. Essa corrente estaria, assim, associada ao pensamento construtivista pós-moderno, sendo os seus expoentes intelectuais progressistas latino-americanos e europeus que apregoam o ecologismo e são próximos aos movimentos sociais. A vertente ecologista e pós-desenvolvimentista tem sido particularmente crítica em relação aos governos de Correa e de Morales, em função do impacto negativo de suas políticas extrativistas sobre o meio ambiente e sobre os interesses e o direito de autodeterminação, reconhecido constitucionalmente, dos povos indígenas. Ademais, o caráter unificador e dirigista de suas políticas concederia pouco espaço às reivindicações de distintos e diversos coletivos sociais, interessados também na construção de seu próprio buen vivir. Críticas a essa corrente incluem sua suposta falta de pragmatismo, seu "ecologismo infantil", nos dizeres de Rafael Correa, e o seu desvirtuamento do caráter ancestral do SK, posto que essa vertente procura combinar ou mesclar elementos das cosmovisões indígena e ocidental.

A terceira e última corrente, dita "indigenista e pachamamista", se distingue pela relevância concedida aos povos indígenas na construção do sumak kawsay e por sua valorização da cosmovisão andina, que é relacional, biocêntrica (e não antropocêntrica), baseada na reciprocidade, na "convivencialidade" e lastreada por uma concepção de tempo que é circular e não linear. Nessa vertente, rejeita-se o termo castelhano buen vivir, em favor do sumak kawsay (ou do suma qamaña), com o intuito de sinalizar a relevância da dimensão espiritual que seria inerente ao SK. O ideal é a (re)criação da supostamente harmoniosa convivência dos povos originários, que davam centralidade ao seu sistema de "comunismo primitivo", de economia autossuficiente, comunitária, equitativa e sustentável. É quase desnecessário dizer que essa vertente está vinculada ao pensamento indígena tradicional, originário ou pré-moderno. Seus expoentes são lideranças indígenas kichwas equatorianas, aymaras bolivianas e quéchuas peruanas, bem como intelectuais indigenistas 
brancos ou mestiços. Ainda de acordo com Hidalgo-Capitán e CubilloGuevara (2014), essa corrente inspira tanto os movimentos indígenas boliviano, equatoriano e peruano quanto a política da Chancelaria boliviana, liderada por David Choquehuanca ${ }^{8}$. São diversas as críticas normalmente endereçadas a essa terceira vertente, relativas a sua falta de pragmatismo, ao seu "indigenismo infantil" (uma vez mais nas palavras de Rafael Correa), ao seu purismo, localismo e pachamamismo excessivos. Critica-se também a sua visão fortemente idealizada do modo de vida indígena (veja-se, por exemplo, ARTARAZ; CALESTANI, 2015; RECASENS, 2014). A crítica desfechada pelo antropólogo hispano-equatoriano Sánchez Parga (2011) é particularmente dura, uma vez que, para ele, o SK/BV seria um "esquema do passado", uma "evasão mental", uma "utopia reacionária” que não serviria para lidar com os problemas atuais.

Se essa tipologia das formas de compreensão do Sumak Kawsay é organizadora desse "rio revolto de ideias e princípios" (BRETÓN; CORTEZ; GARCIA, 2014, p.11), ela também evidencia o fato, hoje amplamente reconhecido e criticado, de que o SK tornou-se uma espécie de "cajón de sastre capaz de albergar concepciones muy distintas - a veces casi antitéticas - en función del punto de vista en que se ubique el observador" (idem). Recasens (2014, p.68), por sua vez, fala da possibilidade de que o BV/SK acabe se convertendo em um "conceito-ameba”. Gudynas (2011), por outro lado, como a maior parte daqueles ativamente envolvidos nisso que às vezes se denomina como uma "revolução cultural e democrática" (ARTARAZ; CALESTANI, 2015, p.217), faz das divergências virtude, ao entender o SK/BV como um "conceito plural em construção", como um "conceito vivo" e como uma "plataforma para ver o mundo de outras maneiras".

Cabe salientarmos, por fim, que, na medida em que o governo Correa foi se distanciando do movimento indígena (TRUJILLO, 2010) e reforçando suas apostas no extrativismo, em contradição com o discurso inaugural da Revolução Cidadã e em oposição frontal ao texto constitucional equatoriano, tornou-se recorrente a tentativa de se distinguir um Buen Vivir próprio dos governos ditos progressistas, por um lado, e, por outro, um Sumak Kawsay ou

\footnotetext{
${ }^{8}$ É por essas e por outras que surgem críticas como a seguinte: Evo Morales solo piensa en la reindigenización de Bolivia y siente una profunda animadversión por Occidente en general, y gringos como dice - y españoles en particular, mientras Rafael Correa quisiera que Ecuador se convirtiera en Suiza (BASTENIER, 2015; p.1).
} 
suma qamaña que seria próprio de atores sociais como o(s) movimento(s) indígena(s) (para uma síntese crítica desse debate, ver GUDYNAS, 2014) ${ }^{9}$. De fato, Manosalvas (2014) afirma que nos "enunciados oficiales [equatorianos] del último año se observa una notable reducción en el uso del término sumak kawsay y el uso casi exclusivo del término buen vivir" (2014; p.114).

Para encerrarmos esta nossa breve discussão acerca das definições de $\mathrm{SK} / \mathrm{BV}$, plurais e divergentes, escutemos Bretón, Cortez e Garcia (2014; p.17), que sintetizam de maneira precisa e elegante a acirrada polêmica definicional:

\begin{abstract}
"Parece claro, pues, que sumak kawsay y buen vivir son conceptos poliédricos, ambivalentes, vaporosos y difíciles de concretar; convergentes o divergentes según el uso ideológico y político que se haga de ellos; que han sido nutridos desde diferentes tradiciones intelectuales y publicitados, en suma, como punta de lanza del fin de una modernidad caduca como anclaje discursivo de nuevos (?o no tan nuevos?) modelos de (re)orientación de las políticas económicas de los regímenes tildados de postneoliberales".
\end{abstract}

Se um dos poucos denominadores comuns na Babel de interpretações e proposições acerca do SK/BV é a referência a valores e princípios ancestrais, como vimos, qualquer breve apreciação da genealogia do termo reserva algumas surpresas. Isso porque esses termos, com a conotação atual, surgem apenas a partir do início do século XXI.

Não nos interessa aqui uma genealogia de caráter etimológico, mas sim os atores e processos que estiveram/estão em disputa pela criação do sentido do temo SK. Interessa-nos a construção da narrativa segundo a qual o SK/BV se tornou o princípio orientador, pelo menos no plano retórico ou declaratório, da ação estatal sob a Revolução Cidadã. Ao fim deste artigo, após analisarmos, nas duas próximas seções, a institucionalização dos conceitos SK/BV e o seu papel na reconfiguração do sistema equatoriano de proteção social durante a era Correa, poderemos, nas conclusões do trabalho, nos posicionarmos acerca do seguinte debate, hoje candente: em que medida

\footnotetext{
${ }^{9}$ Cabe aqui recordarmos que, após o levante indígena de 1990 no Equador, o número e a intensidade das ações coletivas do movimento indígena equatoriano não têm paralelo na América Latina (RODRIGUEZ, 2012).
} 
o governo equatoriano, em sua instrumentalização da ideia de SK/BV, teria, também nessa seara, "sequestrado" e "domesticado" o conceito, como sugerem Gudynas (2014) e alguns outros?

Nossa breve genealogia será, salvo menção explícita em contrário, uma síntese daquela elaborada por Bretón, Cortez e Garcia (2014), que, como nós neste trabalho, estão preocupados com o SK/BV como "tecnologia política de governo". Cabe destacarmos, inicialmente, que o surgimento de uma literatura especializada sobre o $\mathrm{SK} / \mathrm{BV}$ e demais termos e conceitos nativos correlatos aconteceu, "aproximadamente", a partir do ano 2000. Anteriormente, o aporte de disciplinas tão diversas quanto a filosofia, a teologia, a antropologia e a economia não mencionava explicitamente os termos hoje em voga, mesmo que o seu interesse se aproximasse dos temas e questões subsumidos no conceito do SK/BV e de seus correlatos. Varreduras feitas nas crônicas coloniais não reportaram sua existência com a conotação atual. Também a etnografia destaca sua inexistência em investigações prévias ao debate atual (RECASENS, 2014). Os dicionários mais antigos das línguas originárias, por sua vez, registram apenas o uso separado das palavras, que posteriormente foram empregadas e combinadas para a produção de significados distintos.

Antes del año 2000, el sumak kawsay y el buen vivir no aparecían en el espectro disciplinario ecuatoriano que se había investigando desde tiempo atrás en torno a la posibilidad de una filosofía indígena (...) o también andina (...). Lo mismo se puede decir respecto a aportes teológicos que veían en la relación 'mística' de los indígenas con la tierra el fundamento para su 'liberación' (...). En aquella época, intelectuales indígenas que publicaron sobre una 'cosmovisión indígena' (...), una 'visión cósmica' (...) en los Andes o sobre un 'saber andino' o 'ciencia ancestral' (...) tampoco se refirieron explícitamente a los términos en cuestión. Igualmente ocurre respecto a discursos ambientalistas o ecológicos que desde posiciones humanistas reivindicaban no solo un uso de la ciencia y la técnica con criterios de sustentabilidad ambiental, sino también la recuperación de saberes y prácticas con antiguas raíces culturales (...) que pudieran empatar con una perspectiva ecológica. (BRETÓN; CORTEZ; GARCIA, 2014; p.14-15).

Outro ponto de interesse, desta vez questionando o caráter autóctone do conceito de $\mathrm{SK} / \mathrm{BV}$, diz respeito à supostamente "intensa participação", nos períodos anteriores aos candentes debates constitucionais, de organismos 
internacionais interessados em promover a busca e elaboração de propostas de desenvolvimento que se espelhassem em antigas tradições da região. $\mathrm{O}$ papel desempenhado na Bolívia pela GTZ, a Agência Alemã de Cooperação Técnica, e pelo Instituto Goethe é brevemente apontado por Recasens (2014) e por Bretón, Cortez e Garcia (2014). Tratando especificamente do Equador, que tem demonstrado aberto interesse na exportação do ideário (re)fundador da Revolução Cidadã, Monosalvas (2014) afirma que:

A diferencia de lo que ocurría con el modelo neoliberal en el que la voz autorizada era la de los organismos internacionales o con los modelos anteriores en los que la construcción del sistema simbólico correspondía a una red de actores internacionales en foros externos, en este caso la formulación del referencial del buen vivir fue un proceso nacional. Quizá es esto lo que le otorga un sentido de autonomía y novedad frente a las formulaciones anteriores. (p.115-116).

Ainda segundo Bretón et al. (2014), não é casual o fato de que as primeiras sistematizações sobre o SK e congêneres tenham surgido no momento em que se acentuava a crítica ao modelo prevalecente de desenvolvimento, uma vez que era premente, como ainda o é, a busca de respostas ao "déficit ecológicosocial que se agudizó con la instauración, a escala global, de políticas neoliberales en las décadas de ochenta y noventa" (idem, p.17).

$\mathrm{Na}$ próxima seção do trabalho, trataremos da institucionalização do(s) conceito(s) de SK/BV e de sua instrumentalização política pelo governo da Revolução Cidadã. Antes, porém, e para finalizarmos esta primeira seção, discutiremos brevemente a possibilidade, a utilidade e as implicações de entendermos o SK/BV como uma "tradição inventada".

Em seu trabalho, hoje referencial, o historiador britânico Eric Hobsbawn (1984) define "tradição inventada" como:

um conjunto de práticas, normalmente reguladas por regras tácita ou abertamente aceitas; tais práticas, de natureza ritual ou simbólica, visam inculcar certos valores e normas de comportamento através da repetição, o que implica, automaticamente, uma continuação em relação ao passado. Aliás, sempre que possível, tenta-se estabelecer continuidade com um passado histórico apropriado. (1984; p.9).

Se a chamada Constituição de Montecristi conclamava a que Dejemos 
el passado atrás ${ }^{10}$, aos arquitetos da Revolução Cidadã importava, e muito, uma reconstrução seletiva do passado. Decretava-se como passado o caráter excludente do Estado equatoriano, o "colonialismo interno" e a "longa e triste noite neoliberal", no famoso bordão eleitoral de Correa, mas o ideal de futuro bebia explicitamente na fonte da tradição, ainda que seja essa uma "tradição inventada".

Abordar o SK/BV como "tradição inventada" suscita questões epistemológicas e políticas importantes, como apontado por Bretón, Cortez e Garcia (2014), que reconhecem o seu caráter de tradição "legitimamente" inventada:

\begin{abstract}
¿es imaginable la pervivencia en el tiempo de unas ontologías genuinamente andino-amazónicas en contextos de fuerte hibridación cultural, fruto precisamente de la subordinación y racialización secular de esos colectivos subalternos? ¿Estaremos asistiendo a una (re)esencialización de unas 'culturas ancestrales' supuestamente incontaminadas como si estuvieran conservadas entre naftalinas? Si es una tradición de nuevo cuño, ¿se tratará de un proceso de ventriloquia política en virtud del cual algunos hablan en nombre de otros? (BRETÓN; CORTEZ; GARCIA, 2014; p.12-13).
\end{abstract}

Também para Recasens (2014), o BV/SK pode ser pensado como uma "tradição inventada". Isso porque o caráter idealizado da cosmovisão e dos demais valores das culturas andinas, apresentados de maneira monolítica, estática e a-histórica, convertido em alternativa aos padrões convencionais de desenvolvimento, teria contribuído para sobredimensionar e reificar o seu significado.

Neste "riorevoltodeideiase princípios", variadas perspectivasconvivemlado a lado, por vezes de maneira conflitiva, calcadas em distintas epistemologias, modernas, racionalistas, representacionistas ou objetivas, em um extremo, e, no outro, pós-modernas, pós-racionalistas, construtivistas e subjetivas. Se o SK não foi detectado pelos estudos históricos ou antropológicos, ele tem sido inventado e (re)construído a partir de instituições e valores ancestrais e de elementos esparsos da filosofia andina. Herdado, imaginado ou inventado, o

\footnotetext{
${ }^{10}$ Este é o subtítulo da edição da Constituição publicada em 2008 pelo Ministério de Relações Exteriores, Comércio e Integração (ASAMBLEA CONSTITUYENTE, 2008).
} 
Sumak Kawsay tornou-se, no entanto, eixo central da nova Carta Magna, e é a partir dele, ou em seu nome, que parte das políticas públicas do Equador contemporâneo tem se desenvolvido.

\section{Sumak Kawsay ou Buen Vivir? A Institucionalização do Conceito entre a Constituição de 2009 e a "Revolução Cidadã"}

Os objetivos desta seção são apresentar e discutir a maneira como se institucionalizou no Equador a ideia/plataforma do SK/BV durante o governo de Rafael Correa, eleito pela primeira vez em 2006. Serão discutidos os marcos e documentos legais, partidários, programáticos e institucionais que dão concretude ao intuito da chamada Revolução Cidadã, sempre reiterado, de tratar o $\mathrm{SK} / \mathrm{BV}$ como parâmetro e objetivo central da política pública. Comecemos, assim, em desobediência à cronologia, com uma apreciação rápida do caráter inovador da Constituição de 2008, destacando o papel nela ocupado pelo SK/BV.

Talvez seja possível pensarmos a Constituição Equatoriana de 2008, amplamente reconhecida por seu caráter radicalmente inovador, por seu vanguardismo e por seu viés pós-materialista, como produto da convergência de duas forças políticas principais: (a) da transformação do(s) movimento(s) indígena(s) em ator-chave do sistema político do país e (b) do caráter estratégico conferido à Assembleia Constituinte pelo recém-eleito presidente Rafael Correa, que fez da sua convocação elemento central da sua bem acolhida proposta de governo. Ademais, a Alianza PAIS teve mais de $70 \%$ das cadeiras na Constituinte. Vale lembrarmos, também, que a nova "Constituição de Montecristi" entrou em vigor após ser referendada, em setembro de 2008, por 63,9\% dos cidadãos com direito a voto. Se hoje o governo da Revolução Cidadã se encontra apartado do movimento indígena que lhe deu apoio inicialmente, cabe recordarmos que, após o inédito e massivo levante indígena de 28 de maio de 1990 (BREDA, 2011), esse movimento:

“(...) has consistently challenged both the exclusionary character of the Nation-state and imperial-neoliberal impositions like privatization and free trade. Their varied strategies and interventions including massive uprisings, legal demands, electoral involvement, local government transformation, the insertion of 
collective rights, and State participation, have made them political actors that the State can no longer ignore. These interventions have also helped raise awareness in society of the indigenous difference and presence, and enable alliances with other critical sectors". (WALSH, 2010; p.205-206).

Contudo, o processo de elaboração da Constituição de 2008 nos interessa menos que as suas muitas inovações, relacionadas tanto com a questão do acesso ao Estado e às políticas públicas quanto, principalmente, com seu intuito de refundação do Estado e da própria sociedade. Neste sentido, é significativo o já mencionado subtítulo da edição da Constituição publicada em 2008 pelo Ministério de Relações Exteriores, Comércio e Integração: Dejemos el passado atrás (ASAMBLEA CONSTITUYENTE, 2008). Como é unanimemente apontado pelos analistas, o Buen Vivir/Sumak Kawsay se constitui tanto como uma busca de resgate e reconstrução de tradições ancestrais quanto como um horizonte, sendo também o eixo organizador da própria Constituição. Por seu caráter simultaneamente sintético, abrangente e esclarecedor, outra longa citação de Walsh pode nos ser útil. Nela, a autora apresenta as três transformações centrais que a Constituição equatoriana de 2008 procura articular:

"The first transformation finds its ground in the destabilization of
the hegemony and dominion of Western logics and rationalities.
The second transformation is marked by the going beyond or
overcoming of the multicultural constitutional reform of the
1990s that recognized cultural diversity and collective rights
while strengthening the uninational and monocultural structure.
And, the third is a thinking 'with' other logics, rationalities,
and sociocultural-ontological-existence-based modes of life and
living. Together these transformations disturb and disorder the
uninational and monocultural foundations of State and society,
and the neoliberal capitalist frame and model." (WALSH, 2010;
p.206).

Segundo o economista e professor equatoriano Alberto Acosta, que foi Ministro de Energia e Minas do governo Correa, presidente da Assembleia Constituinte e posteriormente candidato dissidente à presidência da República, a tarefa proposta em Montecristi, povoado onde nasceu o líder da Revolução Liberal Eloy Alfaro, e onde funcionou a Constituinte, foi "superar a Constituição neoliberal de 1998” (ACOSTA, 2010; p.2). Ainda segundo 
Acosta, nos trabalhos constituintes para a elaboração da Carta que seria "la mas ecuatoriana de toda la historia" (idem; p.16), um dos pontos medulares do debate foi o questionamento do regime de desenvolvimento então prevalecente. Acosta, um dos mais influentes propugnadores da ideia do BV/ SK, que se tornou o eixo gravitacional da nova Constituição, afirma ainda que o conceito é mais do que uma declaração constitucional, apresentandose como uma "oportunidade para se construir coletivamente um novo regime de desenvolvimento, (...), uma nova forma de vida" (idem; p.7). A Constituição estabelece a necessidade de elaboração do Plano Nacional de Desenvolvimento, a que devem se sujeitar as políticas públicas, e define o $\mathrm{BV} / \mathrm{SK}$ como o principal objetivo do desenvolvimento.

Por sua vez, a Constituição do Estado Plurinacional da Bolívia, promulgada em 2009, país esse cuja população é majoritariamente indígena, ao contrário do Equador, não faz economia de termos nativos e de conceitos ancestrais ao enumerar os princípios ético-morais da sociedade plural em construção no país: "ama qhilla, ama llulla, ama suwa (no seas flojo, no seas mentiroso ni seas ladrón), suma qamaña (vivir bien), nandereko (vida armoniosa), tekokavi (vida buena), ivimaraei (tierra sin mal) y qhapajnan (camino o vida noble)" (CONSTITUCIÓN DEL ESTADO PLURINACIONAL DE BOLIVIA, 2009). A Constituição equatoriana, em contraste, faz menção apenas ao termo kichwa Sumak Kawsay, dando a ele, como vimos, a contestada tradução castelhana de Buen Vivir.

Comparando as novas Constituições da Bolívia e do Equador, Gudynas (2011) nota que, no primeiro caso, suma qamaña e seus conceitos correlatos são apresentados como fundamentos ético-morais, sendo explicitados na definição constitucional de plurinacionalidade. $O$ caso equatoriano seria distinto, uma vez que o SK é apresentado tanto como marco para um conjunto de direitos quanto como "expressão de boa parte da organização e execução desses direitos, não apenas no Estado, mas em toda a sociedade" (p.4). Na Constituição equatoriana, assim, o SK/BV é formalizado de maneira mais ampla e profunda, posto que não se restringe a um princípio ético-moral, figurando de maneira central no conjunto de direitos. Há definido na Constituição Equatoriana, inclusive, um "Régimén del Buen Vivir" (Título VII). O autor enfatiza, ainda, que na Carta equatoriana o SK é "plural, no sentido de abrigar um amplo conjunto de direitos", articulandose, "de forma simultânea, com outros direitos que não se encontram em seu interior" (idem).

Por isso, não chega a surpreender o fato de, na Constituição equatoriana, 
ser mais frequente a menção explícita ao BV/SK: são vinte e três aparições do termo Buen Vivir e cinco do termo Sumak Kawsay, ao passo que, na boliviana, o termo Vivir Bien aparece sete vezes, enquanto o seu equivalente aymara suma qamaña aparece apenas uma única vez (o equivalente kichwa não é mencionado na Constituição boliviana). Destaque-se que, em ambos os casos, é muito mais frequente o uso dos termos em castelhano.

Como já se mencionou, a Constituição equatoriana de Montecristi determina a criação de um Régimen del buen vivir, pensado como um sistema de proteção social baseado em direitos e supostamente capaz de articular a política, a economia, a questão social, a cultura e o meio ambiente.

A Carta Magna equatoriana é também frequentemente mencionada, e inúmeras vezes louvada, por dar ao Equador o status de Estado Plurinacional e Intercultural, por reconhecer a Natureza como sujeito de direitos, pelo aprofundamento dos direitos coletivos e pela explicitação do direito à água como direito humano fundamental. No que diz respeito aos seus reclamos relativos à necessidade de reconfiguração do sistema internacional, a Constituição de Montecristi "impulsa el principio de ciudadania universal, la libre mobilidad de todos los habitantes del planeta y el progresivo fin de la condición de extranjero como elemento transformador de las relaciones desiguales entre los países, especialmente Norte-Sur" (ACOSTA, 2010, p.16). Sobre esse ponto central, cabe recordarmos que o Equador é um Estado que não apenas viveu uma forte diáspora de seus cidadãos, sendo também o país latino-americano que abriga o maior número de imigrantes, a maior parte deles refugiados do conflito doméstico colombiano (MINISTERIO DE RELACIONES EXTERIORES Y MOVILIDAD HUMA, S/D).

Contudo, o conceito/plataforma/ideal do SK/BV não foi "institucionalizado" pela primeira vez no Equador pela Constituição de Montecristi. Já no primeiro programa de governo do Movimiento Alianza PAIS, elaborado para as eleições de 2006 e intitulado "Un primer gran paso para la transformación radical del Ecuador", havia referências ao BV (nesse documento, o termo BV é mencionado apenas quatro vezes, ao passo que o termo kichwa SK simplesmente não aparece). Esse plano de governo, elaborado com a participação de centenas de indivíduos individualmente e de dezenas de representantes de movimentos sociais, é entendido por Alberto Acosta, um protagonista central e depois político e intelectual dissidente, como um dos "documentos fundadores" de todo o processo que se seguiu (ACOSTA, 2014 apud FERNÁNDEZ; PARDO; SALAMANCA, 2014).

Em 2007, primeiro ano do primeiro mandato de Correa, o BV aparece 
pela primeira vez em um documento oficial do Estado Equatoriano, qual seja, o Plano Nacional de Desenvolvimento 2007-2010 - PND 2007 - (BRETÓN; CORTEZ; GARCIA, 2014). No PND 2007, o termo BV aparece três vezes, ao passo que o termo SK não é mencionado.

É também em 2007 que a poderosa CONAIE (Confederação de Nacionalidades Indígenas do Equador) apresenta para a Assembleia Constituinte a sua proposta, que postula como prioridade o reconhecimento constitucional do Equador como um país plurinacional, sendo o Sumak Kawsay mencionado apenas uma única vez, e não no corpo da proposta, mas em sua apresentação (MONOSALVAS, 2014; p.111, rodapé 8). Cabe frisarmos que, na plataforma eleitoral da Alianza PAIS, do ano anterior, prioridade já era concedida ao BV.

Bretón, Cortez e Garcia (2014) sugerem que a estratégica SENPLADES (Secretaria Nacional de Planificación y Desarrollo), que elaborou os Planos Nacionais de Desenvolvimento e é a organização governamental que marca o compasso tecnocrático do governo da Revolução Cidadã, acaba promovendo o distanciamento do Buen Vivir das tradições que sustentavam o Sumak Kawsay, debilitando, no processo, o alcance político da plurinacionalidade, o que não teria acontecido na experiência boliviana.

Alguns autores consideram que o Plano Nacional de Desenvolvimento 2007-2010 (PND 2007), elaborado no primeiro ano do governo Correa, foi um insumo "determinante" tanto na organização da estrutura quanto dos debates da Assembleia Constituinte, que foi instalada em novembro de 2007 (MONOSALVAS, 2014). Em uma Constituinte fortemente dominada pela Alianza PAIS, buscou-se explicitamente traduzir em leis as propostas do PND 2007. O PND 2007, porém, estava fortemente impregnado por uma visão economicista e tecnocrática do desenvolvimento, o que fica evidenciado pela recorrência, no texto, de termos como "crescimento econômico", "crescimento integral", "produtividade", "eficiência" e "competitividade" (RECASENS, 2014; p.59).

Depois que a Constituição de Montecristi foi aprovada e referendada pelo voto popular, foi elaborado um segundo Plano de Desenvolvimento, desta vez sintomaticamente denominado Plano Nacional para el Buen Vivir 2009-2013 (PNBV 2009). Se a Constituição buscou definir um Regime do Buen Vivir, nesse segundo Plano as referências ao "desenvolvimento humano", que constavam do PND 2007, deram espaço, segundo Monosalvas (2014), à formulação do Buen Vivir, "aunque se mantiene el lenguaje seniano de las capacidades" (p.108). Ao contrário do primeiro PND, em que o BV é 
mencionado de maneira sumária, no PNBV 2009 o BV/SK é anunciado como uma "mudança de paradigma". A frequência com que esses dois documentos fazem menção ao BV/SK parece ilustrar a mudança: se no PND 2007 o termo BV aparece três vezes (enquanto o termo SK não aparece nenhuma vez, o que também não deixa de ser significativo), no PNBV 2009 o termo BV aparece 298 vezes (e o termo kichwa SK apenas cinco vezes). Ressalte-se aqui, de passagem, que, depois de aprovada a Constituição, a Alianza PAIS "tendeu a subestimar a contribuição das organizações sociais no processo político" (GALLEGOS; STOESSEL, 2015; p.8), o que parece dar sustentação a sugestões, como a de Gudynas (2014), de que o atual governo do Equador (bem como o da Bolívia), tem tentado "sequestrar o termo, domesticá-lo e usá-lo como símbolo para defender suas ideias e planos” (p.34).

Feito esse breve panorama da institucionalização do conceito de BV/ SK nos documentos que têm procurado dar as diretrizes para o governo da Revolução Cidadã, vejamos, a seguir, o seu impacto sobre a reconfiguração do sistema equatoriano de proteção social.

\section{A "Revolução Cidadã", o Sumak Kawsay / Buen Vivir e a Reconfiguração do Sistema Equatoriano de Proteção Social: Novas Políticas de Assistência Social e de Educação?}

Discutindo a questão do uso da língua inglesa como língua franca no processo da produção das políticas sociais no âmbito da União Europeia, Barbier (2014) aponta o empobrecimento da linguagem das políticas sociais. O seu uso exclusivo teria produzido, como argumenta e evidencia o autor, debates superficiais e, por vezes, autorreferidos sobre a política social, os quais muitas vezes falham em reconhecer variações e especificidades nacionais. Em que medida pensar o bem-estar social e as politicas sociais a partir de conceitos autóctones, resgatados, recriados ou simplesmente inventados, como o Sumak Kawsay/Buen Vivir, poderia produzir ou dar margens para inovações no campo da proteção social? Como se traduz em prática, neste subcampo específico da ação estatal, a "utopia andina”? Ou apenas estaríamos diante de mais uma variante do nacionalismo latino-americano, inócuo na produção de inovações significativas no âmbito das políticas sociais?

Se a proposta de refundação sociopolítica subsumida no ideal de SK/ BV envolve "repensar as necessidades" humanas, partindo da "primazia 
da eficiência" para se atingir alguma forma de institucionalização do "imperativo da suficiência” (RODRÍGUEZ, 2014), pensar sua concretização com seriedade implica não apenas mudanças nos marcos legais e nas políticas públicas, mas também transformação cultural. Implica ainda, nos termos de Artaraz e Calestani (2015; p.2016): "to move from individualized understandings of well-being to collective ones". Ademais, diferentemente de "outras concepções sobre o bem-estar, o BV torna explícita a relação entre direitos humanos, modelo de desenvolvimento e direitos da natureza" (MONOSALVAS, 2014; p.111). Não surpreende, assim, que as dificuldades de tradução prática do conceito sejam tão acentuadas e evidentes, a começar pelo insucesso e/ou capitulação na busca de superação da matriz de desenvolvimento extrativista e do modelo econômico primário-exportador, como atestam inúmeros autores.

Neste contexto, há quem afirme, a exemplo de Domínguez e Caria, que o "único âmbito em que indubitavelmente tem havido avanços significativos nos anos da Revolução Cidadã é no das necessidades básicas (redução da pobreza e da desigualdade, melhora nos indicadores de saúde e educação)" (2014; p.37).

Neste trabalho, contudo, não nos propomos a investigar o impacto efetivo das mudanças que têm sido feitas, desde o início da RC, nas políticas sociais. Interessa-nos, antes de mais nada, verificar se, neste campo específico da ação estatal, a engenharia política equatoriana operou mudanças significativas na lógica de sua atuação, e não apenas no volume dos gastos sociais, na ampliação das coberturas ou na eventual melhor focalização. Para tanto, serão enfatizadas, nesta seção, duas políticas sociais: assistência social e educação.

Antes, porém, cabe recordarmos, muito brevemente, a situação do sistema equatoriano de proteção social anterior ao advento da RC. Uma forma econômica de retratarmos a situação é lembrarmos as maneiras, convergentes, como foi categorizado tal sistema. Tendo como foco os chamados "regimes de bem-estar social" e não apenas o Estado como provedor, Filgueira (1998), analisando o período 1930-1980, caracterizou o regime do Equador como de tipo "excludente". Isso em função do caráter elitista do seu seguro social e das suas políticas de saúde e da natureza dual da sua provisão de educação. Tratava-se, segundo o autor, de um "Estado predador", na célebre definição de Peter Evans. Tendo como foco as décadas de 1980 e 1990, em que prevaleceu o neoliberalismo, Franzoni (2005), em outro estudo comparativo dos regimes latino-americanos, afirma que a experiência equatoriana se 
distingue por seu "familiocentrismo-com-Estados-e-mercados-débeis". Feita esta brevíssima caracterização, passemos agora para a nossa discussão das políticas sociais da Era Correa.

Em um estudo abrangente e provocativo sobre a "caixa de ferramentas" da política social (social policy toolkit) da Onda Rosa latino-americana, Reygadas e Filgueira (2010) apresentam, classificam e analisam as alternativas de políticas sociais adotadas pelos governos de oito países da região no combate às desigualdades ${ }^{11}$. Os autores classificam as políticas sociais priorizadas pelos novos governos de esquerda desses oito países (ou o seu "repertório de estratégias de equalização", que não envolvem apenas políticas sociais), em três categorias principais ${ }^{12}$ : haveria as políticas (ou estratégias) radicais populistas, as social-democratas e as liberais ${ }^{13}$.

Se essas denominações não parecem nada inovadoras, o interesse do trabalho está no fato de ele evidenciar que nenhum dos governos em questão adotou uma estratégia "pura”. Enquanto quatro países adotaram políticas classificadas como "pertencentes" a duas estratégias distintas, os outros quatro implementaram, simultaneamente, políticas que podem ser classificadas como radicais populistas, social-democratas e liberais. No primeiro grupo de países, encontram-se Bolívia, Chile, Uruguai e Venezuela. Segundo o quadro apresentado pelos autores, a Bolívia de Evo Morales e a Venezuela não teriam adotado nenhuma iniciativa tida como liberal, mas implementaram políticas classificadas como radical populistas e social-democratas. O Chile e o Uruguai, por seu turno, não adotaram nenhuma política radical populista, mas suas iniciativas foram tanto do tipo social-democrata quanto do liberal. Os quatro países do "mix total”, que implementaram políticas dos três tipos,

\footnotetext{
${ }^{11}$ Os autores entendem a questão social latino-americana do início do século XXI como uma "segunda crise de incorporação ou inclusão", a ser superada, entre outras, por políticas capazes de reduzir as desigualdades.

${ }^{12}$ Os autores afirmam existir uma quarta estratégia, aquela do "reconhecimento", que não é analisada por eles.

${ }^{13}$ Essas três estratégias envolvem distintas políticas e estão baseadas em diferentes princípios de equalização, quais sejam: (a) estratégia radical populista, que enfatiza a igualdade de resultados: misiones ou campanhas sociais, subsídios, controle de preços e nacionalizações; (b) estratégia social-democrata, que prioriza a igualdade de capacidades: reforma tributária, direitos universais e promoção do desenvolvimento; e (c) estratégia liberal, que valoriza a igualdade de oportunidades: privatizações e programas de transferência condicionada de renda (REYGADAS; FILGUEIRA, 2010).
} 
são Argentina, Brasil, Equador e Nicarágua.

Dado esse panorama, Reygadas e Filgueira (2010) não perdem a oportunidade para criticar a simplista tese das duas esquerdas latinoamericanas, já comentadas no rodapé 3. Não apenas as estratégias adotadas pelos distintos governos divergem significativamente quando comparadas entre si, para além da dicotomia radicais/bolivarianos $\mathrm{X}$ moderados/ pragmáticos, mas também, no interior de cada governo, não há agenda plenamente coerente e monolítica.

Interessa-nos aqui, porém, apenas a "caixa de ferramentas" da política social do governo equatoriano da Revolução Cidadã. Vejamos, então, o mix equatoriano, ainda segundo aqueles autores:

(a) Estratégia radical populista: "declarações de emergência"; controle de preços; subsídios para a farinha, fertilizantes, gás de cozinha e combustíveis; e aumentos salariais para os empregados públicos. Há registros, também, da realização de algumas campanhas sociais, como a Misión Manuela Espejo, de atenção a portadores de necessidades especiais (discapacitados), fruto da cooperação equatoriana com Cuba e Venezuela (VARGAS, 2013).

(b) Estratégia social-democrata: spinning development; nurturing development ("perhaps the Correa government in Ecuador is the one that has placed the most emphasis on development promotion programs"; [Reygadas; Filgueira, 2010; p.182]); Programa de Microcrédito 5-55 e para a juventude; Tarifa de la Dignidad (sobre o consumo de energia elétrica); e reforma tributária progressiva (proposta).

(c) Estratégia liberal: Bono de Desarrollo Humano (o programa equatoriano de transferência condicionada de renda) e Bono de Vivienda.

Como o trabalho de Reygadas e Filgueira foi publicado em 2010 e como sua principal fonte sobre o Equador é um artigo de 2007, que foi o primeiro ano da era Correa, não pretendemos derivar daí uma apreciação sistemática da reconfiguração do sistema equatoriano de proteção social sob a Revolução Cidadã. Contudo, interessa-nos não apenas a explicitação do referido mix ou da estratégia combinada de combate às desigualdades no país, mas também a explicação dada pelos autores para a adoção, por governos de esquerda, de estratégias tipicamente liberais de equalização de oportunidades, como os PTCRs. Sua resposta geral envolve inércia institucional; adaptação e 
aprendizado; limitação de recursos; conveniência política, já que esses programas produzem legitimidade política a baixo custo; e oposição limitada. Ainda de acordo com os autores, "[t]hese have been some of the easiest strategies to pursue with few resources and even fewer political costs" (2010; p.179).

No nosso caso específico, como entender o recurso à típica estratégia liberal de combate à pobreza via programas de transferência condicionada de renda (PTCR) por parte de um governo tão impregnado pela retórica antineoliberal, como o de Rafael Correa? Claro que se pode pensar que, mesmo tendo por base a busca de igualdade de oportunidades, substrato da estratégia liberal, os PTCRs podem sim fazer parte de uma estratégia que se quer e se define como "radical". Ademais, mesmo os PTCRs sendo hoje parte do rol de melhores práticas defendidas e divulgadas por diversas organizações internacionais, no plano regional esse tipo de programa está fortemente associado à experiência do "Brasil de Lula" com o Bolsa Família.

Sabemos que os PTCRs são hoje quase onipresentes na América Latina, sendo também adotados por países de diversas outras regiões (GONNET, 2014). Contudo, o programa do Equador, o Bono de Desarrollo Humano $(\mathrm{BDH})$, é apresentado em um trabalho produzido pelo novo Ministério de Coordenação do Desenvolvimento Social equatoriano como o PTCR “más grande de América Latina en lo que refiere al porcentaje de población al que beneficia (40\% del total de hogares)" e como "el programa pilar del sistema de protección social de Ecuador" (DOBRONSKY; MONCAYO, S/D; p.3).

Pois esse "pilar" do sistema teve sua origem e desenvolvimento prévio em dois governos anteriores, que não apenas foram depostos como se tornaram símbolo da "longa e triste noite neoliberal" que a Revolução Cidadã se propôs a superar. O BDH derivou-se do Bono Solidario (BS), criado em 1998 pelo presidente Jamil Mahuad, o mesmo que dolarizou oficialmente a economia do país em 2000. O Bono Solidario foi instituído, em um contexto prévio à aguda crise econômica e política de 1999/2000, como uma medida compensatória pela eliminação dos subsídios ao gás e à eletricidade, medida neoliberal típica. Com a crise, ampliou-se a relevância da transferência monetária como compensação à perda de poder aquisitivo dos salários e ao aumento do desemprego. Em 2003, outro "presidente constitucional" posteriormente deposto, Lucio Gutiérrez, transformou o BS, que havia adquirido grande cobertura, no atual Bono de Desarrollo Humano (BDH), com o objetivo explícito de ampliar o capital humano da população, como evidenciado pela nova denominação do programa, e de impactar tanto a pobreza conjuntural como a estrutural. Na transição do BS para o BDH, a 
transferência passa a ser condicionada, como é hoje o padrão prevalecente na região (idem).

Como normalmente acontece, o valor da transferência monetária provida pelo BDH sofreu importantes acréscimos. Seu antecessor, o Bono Solidario, foi iniciado com uma transferência de 7 dólares por família. Com a sua transformação em BDH, em 2003, o valor foi elevado para 15 dólares por família, 11,5 dólares por idoso e por portador de necessidades especiais (note-se, também, que o programa passa a beneficiar outros públicos, expandindo a sua cobertura). Em janeiro de 2007, com a ascensão de Correa à presidência, o seu valor foi dobrado, para 30 dólares por família, valor que, em julho de 2009, subiu para 35 dólares (GONZALEZ-ROZADA; PINTO, 2011; p.3). Vale ressaltar, ainda, o fato, aparentemente contraditório, de os benefícios do $\mathrm{BDH}$ serem pagos por bancos privados, o que singulariza a experiência equatoriana (NEHRING, 2012). E isso parece contraditório, porque as reformas sociais produzidas pela RG tiveram um acentuado caráter de centralização e forte concentração no Estado da provisão de bens e serviços sociais (CEPAL, 2013).

Contudo, o aumento no valor do benefício do $\mathrm{BDH}$ para 50 dólares, concedido em 2013, momento em que o preço internacional das commodities já havia despencado, traz uma inovação significativa, reforçando o caráter híbrido, já mencionado, das políticas sociais da RC. Como consta do relatório da Cepal, o aumento do BDH:

"se cubrirá con parte de las ganancias de las entidades privadas del sistema financiero, como también del cobro del impuesto a los activos en el exterior, incrementando su tarifa mensual um 0,25\% para fondos disponibles en entidades extranjeras y de inversiones, y un $0,35 \%$ para subsidiarias ubicadas en paraísos fiscales" (CEPAL, 2013; p.42, Cuadro 16).

Cabe destacarmos que, independentemente da possibilidade de se analisar a manutenção e expansão do $\mathrm{BDH}$ como fruto do hibridismo das políticas públicas da RC, como busca de rápida e eficaz legitimação do novo regime e de dividendos eleitorais: "over the last few years, Ecuador has achieved the second largest poverty reduction in the region and it is one of the few countries to have reduced poverty and inequality simultaneously" (MIDEROS, 2014; p.23). Em um trabalho de 2010, porém, intitulado La pobreza en la 'revolución ciudadana' o ¿pobreza de revolución?, Ponce e Acosta criticam a "preocupante deterioração da situação dos indígenas" do país, que "conspira contra qualquer tentativa 
de desenvolver um Estado plurinacional e equitativo" (p.16).

Vejamos, agora, o ocorrido no campo da política educacional durante a Revolução Cidadã, lembrando que, no Programa de Governo da Alianza Pais de 2006, afirmava-se que a educação "se constituirá en la piedra angular sobre la cual se sustentará nuestro compromisso de alcanzar el desarrollo humano integral" (recorde-se também, como assinalado na seção anterior, que os primeiros documentos da RC, ao contrário do que aconteceria posteriormente, empregam o termo Buen Vivir com muita parcimônia: 4 vezes no Plan de Gobierno 2007-2011 e 3 vezes no PND 2007-1010. Nesses dois documentos não há qualquer menção ao termo Sumak Kawsay). Na verdade, "la revolución educativa y de salud" era um dos cinco "ejes programáticos para la transformación radical del Ecuador" (ALIANZA PAÍS, 2006).

Porém, antes de nos voltarmos para o período pós-2007, cabe recordarmos que, como na América Latina de uma maneira geral, também no Equador as propostas para o aprimoramento da educação, nas últimas duas décadas do século passado, foram baseadas no enfoque dado pelos bancos internacionais de desenvolvimento, sob o artifício das famigeradas "condicionalidades" (ESTEVES, 2008). Na área educacional, como em outros campos da política social, o gasto público, que era de 5,4\% do PIB em 1981, diminuiu continuamente, até atingir 1,8\% em 2000 (LÓPEZ, 2011; p.377). Contudo, a instabilidade política pela qual o Equador ficou conhecido no final do século passado deve ser entendida também como expressão da profunda reação dos movimentos sociais do país às políticas de corte neoliberal, como amplamente reconhecido. Se no período o orçamento da educação foi fortemente reduzido, a ação social conseguiu, também no âmbito educacional, impedir a adoção de uma série de propostas "liberalizantes", que foram listadas por López (2011, p.374) e não serão discriminadas aqui. Recorde-se, também, que foi na década de 1990 que se iniciou a formação do sistema de educação bilíngue no país.

Assim, muito antes da conformação da Aliança País, o movimento social equatoriano já se articulava, com sucesso apenas relativo, na demanda por mais e melhor educação. A partir de 1992, foram realizadas três Consultas Nacionais "Educación Siglo XXI", que mobilizaram diversos setores da sociedade e resultaram, em 2006, na elaboração do Plano Decenal 20062015, que incorporou também os compromissos internacionais assumidos pelo país (LÓPEZ, 2010). Uma consulta popular realizada em novembro de 2006 aprovou o Plano Decenal com mais de 66\% dos votos. De acordo com López, esse Plano viria a se constituir como a essência da proposta educativa 
dos primeiros tempos da Revolução Cidadã. O Plano Decenal, entre outras determinações, estabeleceu o aumento anual de $0,5 \%$ no orçamento da educação (não incluindo a educação superior), até que se chegasse a pelo menos $6 \%$ do PIB, meta essa que não foi atingida, mesmo com a onda do superciclo internacional das commodities, do qual se beneficiou também o Equador, em razão, principalmente, de suas exportações de petróleo.

Contudo, já em novembro de 2007, Correa lançou quatro decretos executivos (ESTEVES, 2008) que refletiriam as ambiguidades da política educacional que viria a ser efetivamente implementada pela RC. Isso porque, ao buscar recuperar o papel diretor da política por parte do Ministério da Educação, revertendo descentralizações, desconcentrações e "devoluções" da década de 1990, tais decretos colocariam o Ministério em aberto confronto com os trabalhadores do setor. Esse confronto se deu porque a centralização implicava também a redução do controle exercido pelos sindicatos sobre o sistema educativo público, a busca de melhorar a formação inicial dos professores, o controle sobre a seleção de docentes e a limitação no tempo de exercício dos cargos de direção nas escolas (idem).

Um estudo da Cepal (2013), que caracteriza a evolução do sistema equatoriano de proteção social nas últimas décadas, destacou quatro iniciativas como inovações do governo Correa no campo educacional: a implementação de um novo processo de seleção de professores para o Sistema Educativo Nacional; a criação do Sistema de Evaluación y Rendición de Cuentas (SER) do sistema educativo; a diminuição do poder dos sindicatos (gremios) do setor educativo, o que foi feito por meio de uma reforma na lei da carreira docente; e, por fim, a extinção das unidades executoras autônomas dos serviços educacionais (CEPAL, 2013; p.13, cuadro 1). Outros avanços destacados no relatório dizem respeito à infraestrutura educativa, à melhoria no equipamento, à contratação de novos docentes e à adoção de novas políticas de avaliação e de profissionalização docente. As debilidades ainda pendentes de solução, segundo a mesma fonte, estariam relacionadas à "rigidez de los métodos de enseñanza, la convencionalidad de los enfoques y estratégias pedagógicas, la insuficiente renovación y actualización de sus recursos humanos, y la reestructura integral del sistema" (idem; p.45, rodapé 20).

Como destacam Ribeiro e Passos (2012), a Lei de Educação Geral do Equador, de 2009, não abole a educação particular, que havia sido reconhecida como legítima na Constituição de Montecristi (art.345), mas proíbe que ela tenha fins lucrativos. As escolas particulares devem reinvestir todo o seu excedente de recursos na própria instituição. Os 
valores dos custos repassados aos alunos (que devem ser entendidos como os vouchers tão acidamente criticados pelas esquerdas na década de 1990) seriam estabelecidos pela Autoridade Educativa Nacional, cabendo também ao Estado, além da avaliação dos docentes, a verificação da qualidade da instituição e da formação de seus professores.

Ainda no que diz respeito a essa nova legislação, mesmo vozes críticas como López (2010) reconhecem os seus avanços. Contudo, o autor afirma que foi a articulação do magistério com demais forças sociais que conseguiu vencer a "prepotência do governo e sua maioria na Assembleia Legislativa" (p.385). O suposto caráter "emancipador" dessa articulação teria, inclusive, sido responsável pela denominação da lei como Ley Orgánica de Educación Intercultural, que se contrapõe ao fato de o governo, traindo o uso indiscriminado que faz da expressão "revolução educativa", não ter considerado, em sua proposta, o caráter plurinacional e intercultural do Estado equatoriano (idem).

No que concerne à avaliação docente, sempre tão polêmica, a Ley de Carrera Docente y Escalafón del Magisterio Nacional de Ecuador estabelece, em seu Artigo 38, que os docentes que, por duas vezes consecutivas, obtiverem resultado "insatisfatório" na avaliação de desempenho, "serán separados del magistério" (apud TELLO; ALMEIDA, 2014; p.172). Esses autores, preocupados especificamente com as políticas docentes na América Latina e com suas continuidades e rupturas no período pós-neoliberal, afirmam que, no Equador, teria havido sim uma ruptura com os preceitos neoliberais, em função do forte controle estatal imprimido pela Revolução Cidadã, como vimos. Contudo, os autores chamam a atenção para o fato de um governo latino-americano sintonizado com o chamado Socialismo do Século XXI responder "ao mandato neoliberal nos termos de accountability e regulação docente" (idem).

No campo da política educacional, assim, parece se reproduzir o hibridismo de estratégias apontado por Reygadas e Filgueira (2010). Além, é claro, de as iniciativas do governo da Revolução Cidadã, por seu continuísmo, por sua falta de ousadia e pelo caráter fragmentado e pontual de suas inovações não estarem à altura das expectativas suscitadas pelo discurso rupturista e pelo horizonte de esperanças desenhado pela ideia/ plataforma do Buen Vivir/Sumak Kawsay. Vale lembrar, porém, que, segundo o Latin American Public Opinion Project (LAPOP), os equatorianos fizeram, em 2014, a segunda melhor avaliação, na América Latina, dos serviços públicos de educação e saúde (apud López, 2015). 


\section{Considerações Finais}

Medido pela taxa de crescimento médio anual do gasto social do Orçamento Geral do Estado equatoriano, parece significativa a priorização da política social por parte do governo Correa. Isso porque, no período 2000-2006, essa taxa foi de 5,6\%, enquanto no período 2007-2012 ela foi de 15\% (CEPAL, 2013; p.23). O fato de essa inflexão ter sido em parte proporcionada pelo boom das commodities não precisa ser superexplorado nestas nossas considerações finais. Por outro lado, um quadro um tanto distinto é revelado quando se observa o ocorrido com a questão da pobreza. Segundo a mesma fonte, enquanto entre 2000 e 2006 a incidência da pobreza, no plano nacional, se reduziu 25,3\%, passando de 62,9\% para 37,6\%, entre 2007 e 2012 ela se reduziu "apenas" 10 pontos percentuais, passando de $36,7 \%$ para $27,3 \%$ (idem, p.11). Mesmo reconhecendo que, a partir de um ponto, a redução vai se tornando cada vez mais difícil, o contraste entre os dois períodos não deixa de parecer contraditório em relação à retórica oficial do Buen Vivir/ Sumak Kawsay ${ }^{14}$.

A esse panorama devemos acrescentar o fato de hoje parecer inquestionável a caracterização do modelo de desenvolvimento fomentado por Correa (e também por Evo Morales) como um "neoextrativismo progressista" (RECASENS, 2014).

No seu panorama mais geral da evolução do sistema de proteção social equatoriano, a Cepal (2013), reconhecendo os avanços da Revolução Cidadã, afirma que, no entanto, as inovações foram poucas. "La mayoria de los cambios aplicados más bien constituyen ajustes a los instrumentos de politicas sectoriales ya existentes, antes que innovaciones a los sistemas propriamente" (p.13). "En esencia se mantiene el viejo esquema de funcionamento combinado con algunas nuevas medidas" (idem), como também ficou claro nos dois casos estudados mais detidamente neste artigo.

Se, como sugere Walsh, "the new Ecuadorian Constitution turns on its head the dominant geopolitics of knowledge" (2010; p.208), a prática política e as

\footnotetext{
${ }^{14}$ Para uma visão bem mais otimista, que destaca as reformas na estrutura institucional da provisão estatal de bem-estar social no Equador da Revolução Cidadã, que buscou promover a intersetorialidade, a coordenação das ações estatais e uma maior interação entre política social e política econômica, ver Nehring (2012). Contudo, como critica o próprio autor, essas reformas produziram uma grande e pesada burocracia, problema esse também apontado pela Cepal (2013).
} 
políticas públicas da Revolução Cidadã têm se mostrado claramente aquém de sua retórica e das expectativas suscitadas. O exemplo equatoriano parece ser apenas mais uma comprovação empírica da tese segundo a qual os governos, em vez de maximizadores, acabam se contentando com o papel de "satisfazedores".

Outra interpretação possível nos é brindada por Peralta, para quem o "correísmo" está:

\begin{abstract}
"demasiado imbuido de acción racional, modernización técnica e imitación tecnocrática de los países económicamente exitosos, como para conectar en un nivel más profundo con las identidades populares. No hay fatalidad alguna en esa opción tecnocrática; habría podido ser diferente. Pero el peso enorme del marketing y del saber técnico ha tendido a excluir la participación, o al menos la sensación de participación protagónica de los de abajo en el proceso de cambio". (PERALTA, 2015; p.5)
\end{abstract}

Seria possível a combinação entre tecnocracia, criminalização da dissidência e da crítica social, como hoje amplamente documentado no Equador, e Buen Vivir/Sumak Kawsay? Seja como for, ao fim e ao cabo, com o passar do tempo o BV/SK tornou-se, para o governo Correa, pouco mais do que marketing, como hoje se reconhece em muitos quadrantes. Vale terminarmos com o desabafo de Alberto Acosta, que, depois de fundar o Alianza Pais, ser ministro de Correa, presidir a Assembleia Constituinte e escrever de maneira prolífica sobre o BV/SK, há anos tornou-se um dissidente:

No se quiere hacer una verdadera revolución, no se quiere cumplir lo que manda la Constitución ni hacer realidad el buen vivir, no hay voluntad política de cambio. Como dice Juan Cuvi, un luchador incansable por la democracia y la justicia, el presidente Correa "no estaba para alternativas, mucho menos para revoluciones, y peor aún para utopías. El desarrollismo, la eficacia tecnocrática, la provisión de in-fraestructura y el incremento del consumo no son más que emulaciones de modelos anclados en viejos patrones colonialistas". (ACOSTA apud FERNÁNDEZ; PARDO; SALAMANCA, 2014; p.114). 


\section{REFERÊNCIAS}

ACOSTA, Alberto.

(2015). El buen vivir, una alternativa por construir. Ecuador Debate, No.75, pp.33-48, 2009.

ARTARAZ, Kepa; CALESTANI, Melania. (2014) Suma qamanã in Bolivia. Indigenous understandings of well-being and their contribution to a post-neoliberal paradigm. Latin American Perspectives, Issue 204, Vol.42, No.5.

(2010). El buen vivir, una utopía por (re) construir. Boletín ECOS, No. 11.

ASAMBLEA CONSTITUYENTE.

(2008). Constitución de la Republica del Ecuador.

Quito, Ministerio de Relaciones Exteriores, Comercio e Integración, 217 p.

AYLLÓN, Bruno; DOLCETTI, Michele.

(2014). Revolución ciudadana, Buen Vivir y cooperación en Ecuador (2007-2013). Relaciones Internacionales, No.46; p.177-199.

BARBIER, Jean-Claude.

(2014). Languages of "social policy" at the EU level. In: BÉLAND, Daniel; PETERSEN, Klaus (Eds.). Analysing social policy concepts and language: comparative and transnational perspectives. Bristol, Policy Press; p.59-80.

BASTENIER, M.A.

(2015). Las revoluciones andinas. A Bolivia y Ecuador les está creando problemas el componente indígena de sus países. El País, 4 de agosto de 2015. Disponivel em: <http://internacional. elpais.com/internacional/2015/08/04/ actualidad/1438704807_295256.html> Acesso em: 28 de setembro de 2015.

BREDA, Tadeu.

(2011). O Equador é verde. Rafael Correa e os paradigmas do desenvolvimento. São Paulo, Elefante Editora.

BRETÓN, Víctor; CORTEZ, David; GARCÍA, Fernando.

(2014). En Busca del Sumak Kawsay. Presentación del Dossier. Íconos Revista de Ciencias Sociales, n. 48; p.9-24.
CAMERON, Maxwell A.

(2009). Latin America's Left Turns: beyond good and bad. Third World Quaterly, v.30, n.2.

CAMERON, Maxwell A. \& HERSHBERG, Eric.

(2010). Latin America's Left Turns: politics, policies, and trajectories of change. London, Lynne Rienner Publishers.

CASTANEDA, Jorge $\mathrm{G}$.

(2006). Latin America's Left Turn. Foreign Affairs, v.83, n. 3.

CEPAL.

(2013). Sistemas de protección social en América Latina y el Caribe: Ecuador. Santiago, Cepal, $81 \mathrm{p}$.

ESTERMANN, Josef.

(2013). Ecosofia andina: un paradigma alternativo de convivencia cósmica y de Vivir Bien. Faia, Vol.II, No.IX-X.

DOBRONSKY, José Martínez; MONCAYO, José A. Rosero.

(2015). Impacto del Bono de Desarrollo Humano en el Trabajo Infantil. Quito, Ministerio de Coordinación de Desarollo Social del Ecuador. s/d. Disponível em: http://white.oit.org.pe/ ipec/documentos/tmc_ecuador.pdf. Acesso em 23 de abril de 2015.

DOMÍNGUEZ, Rafael; CARIA, Sara.

(2014). La ideologia del Buen Vivir: La metamorfosis de una "alternativa al desarrollo" en desarrollo de toda la vida. Pre-textos para el debate, No.2. Universidad Andina Simón Bolívar, Quito.

ESTEVES, Ana.

(2008). Introdución. In: Carlos Arcos Cabrera; Betty Espinosa (Eds.); Desafios para la educación en el Ecuador: calidad y equidad. Quito, Flacso.

FERNÁNDEZ, Blanca; PARD0, Liliana; SALAMANCA, Katherine.

(2014). El Buen Vivir en Ecuador. ?Marketing político o proyecto en disputa? Un diálogo con Alberto Acosta. Íconos Revista de Ciencias Sociales, n. 48, p.101-117. 
FILGUEIRA, Fernando.

(1998). El nuevo modelo de prestaciones sociales en América Latina: eficiencia, residualismo y ciudadanía estratificada. In: Bryan Roberts(Ed.); Ciudadania y política social. San José, FLACSO/SSRC, p.71-116.

FRANZONI, Juliana Martínez.

(2005). La pieza que faltaba: uso del tiempo y regímenes de bienestar en América Latina. Nueva Sociedad, No.199; p. 35-52.

GALLEGOS, Franklin Ramírez \& STOESSEL, Soledad.

(2015). Campos de conflitividade política e movimentos sociais no Equador da Revolução Cidadã. Plural, Vol.22, No.1; p.4-29.

GONNET, Cecilia Osorio.

(2014). CCTs: the "perfect" programs. How epistemic community and international governmental organization do created a consensus about CCTs in Latin America. Trabalho apresentado no "XXIII World Congress of Political Science". Montreal.

GONZALES-ROZADA, Martin; PINTO, Freddy Llerena.

(2011). The Effects of a Conditional Transfer Program on the Labor Market: The Human Development Bonus in Ecuador. Seminário Díalogo Regional de Política Laboral y Seguridad Social. Washington, 20 de abril de 2011.

GUDYNAS, Eduardo.

(2014). Buen Vivir: Sobre Secuestros, Domesticaciones, Rescates y Alternativas. In.: FREIRE, Atawallpa Oviedo (ed.). Bifurcación del Buen Vivir y el Sumak Kawsay. Quito, Ediciones Yachay; p.23-45.

(2013). El Malestar Moderno con el Buen Vivir: Reacciones y Resistencias frente a una alternativa al desarollo. Ecuador Debate, n.88.

(2011). Buen Vivir: Germinando Alternativas al Desarollo. America Latina en Movimiento on line, 2011. Disponível em: < http://www. alainet.org/es/active/48052>. Acesso em 02 de outubro de 2015.
HIDALGO-CAPITÁN, Antonio Luis; CUBILLOGUEVARA, Ana Patricia.

(2014). Seis Debates Abiertos sobre el Sumak Kawsay. Íconos Revista de Ciencias Sociales, n.48.

HOBSBAWN, Eric.

(1984). Introdução: a invenção das tradições. In: HOBSBAWN, Eric; RANGER, Terence (Orgs.). A invenção das tradições. Rio de Janeiro, Ed. Paz e Terra.

LÓPEZ, Alejandra Peña.

(2015). ¿Hacia un Estado meritocrático? Revista Nueva Sociedad, No. 258.

LÓPEZ, Edgar Isch.

(2011). Las actuales propuestas y desáfios en Eduación: el caso Ecuatoriano. Revista Educação e Sociedade, Vol.32, No.115.

MACAS, Luis.

(2010). Sumak Kawsay: la vida en plenitud. Revista América Latina en Movimiento, No.452, Año XXXIV.

MANOSALVAS, Margarita.

(2014). Buen Vivir o Sumak Kawsay. En busca de nuevos referenciales para la acción pública en Ecuador. Íconos Revista de Ciencias Sociales, n. 49.

MENDOZA, Plinio Apuleyo; MONTANER, Carlos Alberto \& LLOSA, Álvaro Vargas.

(2014). Últimas noticias del nuevo idiota iberoamericano. Bogotá, Planeta.

MIDEROS, Andrés Ivan.

(2014). Social protection and poverty eradication in Ecuador. In: CECCHINI, S.; LAVIGNE, M. (Eds.). Public policies for equality. Towards universal social protection systems. Santiago, ECLAC Seminars and Conferences Series, No.78.

MINISTERIO DE RELACIONES EXTERIORES $Y$ MOVILIDAD HUMANA.

Soberanía nacional y política exterior de la Revolución Ciudadana. Quito, Cancilleria Ecuador, s/d. Disponível em: http:// www.cancilleria.gob.ec/wp-content/ uploads/2014/08/Soberan\%C3\%ADaNacional-y-Pol\%C3\%ADtica-Exterior.pdf. 
NEHRING, Ryan.

(2012). Social protection in Ecuador: a new vision for inclusive growth. International Policy Centre for Inclusive Growth Research Brief, n.28.

PARGA, José Sánchez.

(2011). Discursos retrorevolucionarios: Sumak Kawsay, derechos de la naturaleza y otros pachamamismos. Ecuador Debate, 84; p.3150.

PERALTA, Pablo 0spina.

(2015). ¿Por qué protestan en Ecuador? Revista Nueva Sociedad, No.258.

PETKOFF, Teodoro.

(2005). Las dos izquierdas. Nueva Sociedad, n. 197.

PONCE, Juan; ACOSTA, Alberto.

(2010). La pobreza en la "revolución ciudadana" o ¿pobreza de revolución? Revista Ecuador Debate, No.81; p.7-20.

RECASENS, Andreu Viola.

(2014). Discursos "pachamamistas" versus politicas desarollistas: el debate sobre el Sumak Kawsay en los Andes. Íconos Revista de Ciencias Sociales, n.48; p.55-72.

RIBEIRO, Erivane Rocha; PASSOS, Geovanna. (2012). América Latina: políticas educacionais no Equador. Revista Educação e Políticas em Debate, Vol. 2, No.2; p.325-345.

RODRIGUEZ, Edwin Cruz.

(2014). Prolegómenos al vivir bien-buen vivir: una evaluación normativa y práctica. Revista Finanzas y Política Económica, Vol.6, No.2; p.387-402.

(2012). Comparando movimientos indígenas: Bolivia y Ecuador (1990-2008). Íconos Revista de Ciencias Sociales, No. 44; p.35-48.

SILVA, Fabricio Pereira da.

(2010). Esquerdas latino-americanas: uma tipologia é possivel? Revista Oikos, Rio de Janeiro, v.9, n.2.
TELLO, César; ALMEIDA, Maria de Lourdes Pinto de.

(2014). Políticas educativas e profissionalização docente na América Latina. Revista Lusófona de Educação, No.26; p.161-174.

TORRE, Carlos de la.

(2013a). El Tecnopopulismo de Rafael Correa. ¿Es compatible el carisma con la tecnocracia? Latin American Research Review, vol.48, No.1; p. 24-43.

(2013b). Technocratic Populism in Ecuador. Journal of Democracy, Vol. 24, No.3; p.33-47.

TRUJILL0, Jorge León.

(2010). Las organizaciones indígenas y el gobierno de Rafael Correa. Íconos Revista de Ciencias Sociales, No.37; p.13-23.

VARGAS, José Antonio Monje.

(2013). Misión "Manuela Espejo", paradigma de la solidaridad convertida en política de Estado en Ecuador. Revista Cubana de Salud Pública. Vol. 39, n.3; p.598-608.

WALSH, Catherine.

(2010). Political Epistemic Insurgency, Social Movements and the refounding of the State. In.: MORAÑA, Mabel; GUSTAFSON, Bret (eds.). Rethinking Intellectuals in Latin America. Madrid, Iberoamericana; p.199-211.

ZEPEDA, Beatriz; EGAS, Maria Gabriela.

(2011). La política exterior de la revolución ciudadana: opinión y actitudes públicas. Revista Mexicana de Política Exterior, No.93; p.95-134.

\section{Recebido em}

outubro de 2015

\section{Aprovado em}

junho de 2016 